\title{
WAWASAN UNTUK KEPALA SEKOLAH YANG SIBUK
}

\section{Ahmad Mahmudi}

Universitas Nahdlatul Ulama Sidoarjo

\section{PENDAHULUAN}

Pendidikan Indonesia membutuhkan peningkatan akses, mutu dan relevansi pendidikan untuk memberi manfaat membangun bagi pendidikan dan rakyat Indonesia (Irawan et al., 2018). Apakah anda seorang kepala sekolah atau wirausahawan pendidikan?. Apakah Anda baru dalam pekerjaan mengelola sekolah itu atau telah mengelola sekolah selama bertahun-tahun, itu bisa menjadi sangat luar biasa mengikuti jadwal sibuk seorang administrator sekolah. Beberapa teknik manajemen sekolah yang efektif ini layak untuk industri dan dijamin untuk membantu kepala sekolah dan kepala sekolah 
tersibuk menjaga hal-hal di bawah kendali. Anda dapat membuat perbedaan di sekolah atau komunitas Anda. Ini dimulai dengan berfokus pada minat Anda, belajar tentang kemampuan kepemimpinan Anda, dan mencari kegiatan baru dan menantang untuk menerapkannya dan membangun keterampilan Anda. Anda akan membantu membentuk dunia tempat Anda hidup saat ini dan di masa depan. Berikut adalah beberapa wawasan untuk membantu anda menjalankan sekolah dan bisnis pendidikan dengan baik.

\section{MEMBANGUN HUBUNGAN}

Semua yang saya baca tentang kepemimpinan dan semua yang saya alami telah mengajarkan saya bahwa kepemimpinan adalah tentang membangun hubungan. Tidak ada pria atau wanita super. Hanya ada pembangun hubungan super yang memiliki staf yang bersedia 
untuk mencapai visi seorang pemimpin (Bauer, 2019).

\section{HARI PERTAMA PENTING}

Kesan pertama memiliki dampak yang bertahan lama, jadi pilihlah dengan hati-hati. Sebagian besar kelas mengambil hari pertama untuk meninjau silabus. Tempatkan diri Anda pada posisi siswa Anda. Bayangkan pergi dari kamar ke kamar, mendengarkan dengung aturan tanpa henti. Model ini membuat siswa gagal, karena kebosanan mengambil alih dan timbul masalah perilaku. Lewati Silabus, Sebagai gantinya, lakukan kegiatan yang mengatur nada untuk kelas Anda. Melalui kegiatan ini, tunjukkan aturan dan harapan Anda. Siswa akan belajar lebih banyak, dan Anda akan cenderung harus berurusan dengan masalah disiplin pada hari pertama (Kane, 2018). 


\section{EDUPRENEUR}

Edupreneur atau educational entrepreneur berasal dari dua kata yaitu education bermakna pendidikan dan entrepreneur bermakna pengusaha atau wirausahawan. Ada juga yang menyamakan istilah edupreneur dengan istilah teacherpreneur (Purnomo, 2017). Menjaga hubungan baik dengan wali siswa melalui melaksanakan janji dan pelayanan yang baik adalah bagian dari promosi wirausaha (Asitah, Usmawati, Rosyidah, \& Purnomo, 2017). Toleransi, bekerja sama, bertanggungjawab, dan amanah adalah prinsip wirausaha pendidikan (Nahdiyah, Amrina, Purnomo, \& Rosyidah, 2017).

\section{BANGUN TIM}

Saat Anda mengembangkan hubungan dalam organisasi, catat kekuatan semua orang. Bangun tim Anda di atas potongan gratis. Faktanya, bangun tim untuk memperkuat 
kelemahan Anda sebagai seorang pemimpin. Para pemimpin sekolah yang efektif membangun tim yang dapat mendukung upaya mereka (Bauer, 2019). Manajemen sekolah dilakukan dengan menerapkan standar kualitas dalam rekrutmen pengajar yaitu kedekatannya dengan amaliyah (Munjidah, Zannah, Purnomo, \& Rosyidah, 2017).

\section{SPIRITUAL QUETIENT}

Pendidikan adalah kunci untuk membuka pintu emas kesuksesan. Wirausaha pendidikan dengan motivasi bisnis dengan Allah Ta'ala sebagai bentuk kenyamanan untuk ibadah. Tips mengelola institusi pendidikan adalah niat mendidik dan berjuang karena Allah ta'ala. Niscaya rintangan sebesar apapun akan terasa ringan dihadapan kita. Melihat anak mengenal Allah Ta'ala dan sukses akhlak dan pengetahuannya merupakan kebahagiaan pendidik (Yuniarti, Kautsari, Sholichah, Purnomo, \& Rosyidah, 2017). Hubungan pendidikan antara 
guru dan murid itu seperti aliran listrik dengan lampu. Bagaimana lampu itu bisa menyala kalau aliran listriknya juga mati ?. Bagaimana murid itu bisa berprestasi sedangkan guru sendiri tidak pernah berprestasi dan mendoakan (Fidiana, Istiana, Rosyidah, \& Purnomo, 2017). Setiap manusia hamba Tuhan yang memiliki ilmu selayaknya harus mengamalkan ilmu tersebut (Asitah et al., 2017). Prinsip pendidikan adalah sosial. Sebagai seorang guru, kita harus memiliki kepedulian sosial (Asitah et al., 2017). Guru harus bisa membangun generasi muda untuk masa depan. Hiduplah untuk mengamalkan ilmu (Sholichah, Istiqomah, Rosyidah, \& Purnomo, 2017). Cara memimpin sekolah adalah senantiasa musyawarah serta sharing bersama para guru atau dengan siapapun dan tetap mendekat pada Allah SWT (Yuniarti et al., 2017). 


\section{KEMBANGKAN HUBUNGAN DENGAN PARA}

\section{SISWA}

Jika kita ingin siswa mengikuti kita, mereka tidak hanya perlu menghormati kita, tetapi juga menciptakan kesan bahwa kita peduli pada mereka. Selalu tulus, baik hati, mudah didekati, dan siap mengakui kesalahan. Selain itu, siswa harus diberi pujian, dan menunjukkan bahwa Anda mencintai mereka. Dengan kualitas di atas, Anda akan dapat menciptakan hubungan yang baik dengan siswa (Edsys, 2016).

\section{TETAPKAN PRIORITAS YANG JELAS}

(Murray, 2018) menjelaskan Diskusi tentang manajemen waktu yang efektif dimulai dengan penilaian prioritas seseorang, tugas dan tanggung jawab yang paling penting dalam memimpin sekolah. Menurut (Covey, 1996) contoh prioritas ini termasuk, tetapi tidak terbatas pada, berikut ini: 
- Budaya: menciptakan lingkungan yang aman di mana fokusnya adalah pada akademik dan pribadi

- pertumbuhan siswa

- Misi: menyatukan fakultas, siswa, dan orang tua dengan tujuan dan tujuan yang sama

- penglihatan

- Instruksi: pembinaan dan mendukung pengajaran yang sangat baik di setiap kelas

- Kolaborasi: mempromosikan dan memelihara berbagi ide dan sumber daya secara konstan

- Mempekerjakan: menggunakan setiap lowongan untuk mendatangkan guru yang berkualitas

- Alignment: menghubungkan kurikulum dan penilaian dengan standar yang relevan 
- Sumber: bekerja untuk memberi guru alat yang mereka butuhkan untuk berhasil

- Orang tua: membangun hubungan yang kuat dengan keluarga untuk mendukung pembelajaran siswa.

\section{MENGHADIRI AKTIVITAS}

Para pemimpin harus menghadiri acaraacara olahraga, tentu saja, tetapi mereka juga harus menghadiri acara-acara dengan kehadiran yang jarang. Mereka perlu menunjukkan kepada anggota klub akademik seperti tim debat dan Mathletes, anggota band, kelompok teater, dan bahkan siswa dalam kegiatan ekstrakurikuler yang tidak berorientasi pada audiens atau kompetisi yang mereka minati dengan apa yang dilakukan semua siswa. Jika para pemimpin memiliki kebanggaan sekolah, para siswa dan guru juga mungkin (Watanabe-Crockett, 2018). 


\section{PILIH PERTEMPURAN ANDA}

Pemimpin sekolah dan wirausaha pendidikan seharusnya senantiasa menikmati proses karena tidak ada hal yang besar yang tidak dilakukan dari hal yang kecil. Semua butuh proses, karena kesuksesan tidak datang secara langsung tanpa berproses (Maula, Mufidah, Rosyidah, \& Purnomo, 2017). Sadarilah bahwa tidak setiap masalah perlu ditangani. Identifikasi apa yang Anda perjuangkan dan perjuangkan untuk apa yang penting (Drewitt, 2017).

\section{TARGET PRIBADI}

Tetapkan tujuan pribadi dan profesional Anda sendiri setiap tahun. Kunjungi kembali sasaransasaran ini setiap minggu untuk membuat Anda tetap fokus. Masukkan kesehatan, kebugaran, istirahat, pembaruan, dan petualangan terencana dalam tujuan pribadi Anda karena ini akan membantu Anda menjadi waspada, fokus, dan 
kreatif. Anda tidak dapat memimpin orang lain jika Anda tidak dapat memimpin diri sendiri! (Driscoll, 2018).

\section{CATATAN PENDIDIKAN}

Pendidikan itu sebuah perhiasan dalam kemakmuran dan tempat bernaung dalam kesengsaraan (Maula et al., 2017). Hasil penelitian menunjukkan bahwa penerapan pembelajaran dapat meningkatkan prestasi siswa; dan tes menunjukkan bahwa prestasi belajar siswa kelas belajar lebih baik daripada siswa kelas konvensional (Iskandar, Rizal, Kurniasih, Sutiksno, \& Purnomo, 2018). Guru merupakan seorang yag memilki tugas mulia sebagai pendidik dan pengajar sekaligus sebagai pembentuk kepribadian siswa (Maula et al., 2018). Cari ilmu yang bermanfaat dan patuhi aturan-aturan yang ada. Bijaksana dan pantang menyerah dalam belajar adalah kunci kesuksesan. Pendidikan adalah pelajaran yang 
harus kita pelajari setiap hari baik dari buku, lingkungan, teman, maupun keluarga agar kita tidak tertinggal (Qori'ah, Sholichah, Purnomo, \& Rosyidah, 2017).

\section{JADILAH PEMANDU SORAK ANDA SENDIRI}

Terus katakan pada diri sendiri, "Anda bisa melakukannya!" Temukan kekuatan dan keberanian untuk terus berjalan di dalam diri Anda (Drewitt, 2017). Siswa perlu memahami apa yang diketahui dan apa yang diminta untuk memiliki kemampuan menjawab (Suci et al., 2018).

\section{MEMAHAMI KEUANGAN SEKOLAH}

Panduan keuangan memiliki informasi tentang sumber pendanaan, membuat akun, menyiapkan anggaran, dan melaporkan keuangan sekolah (Educational Leaders, 2019). Guru merupakan seorang pendidik dan pengajar 
sekaligus sebagai pembentuk kepribadian siswa yang unggul, berwawasan dan baik (Maula et al., 2018).

\section{CARI SOLUSI JANGKA PANJANG UNTUK}

\section{MASALAH}

Tips kelola sekolah adalah senantiasa belajar dan bekerja keras. Bersabarlah dengan masalah, sesungguhnya didalam kesulitan ada kemudahan (Sholichah et al., 2017). Perbaikan cepat jarang merupakan solusi yang tepat. Solusi jangka panjang membutuhkan lebih banyak waktu dan upaya di awal. Namun, mereka biasanya menghemat waktu Anda dalam jangka panjang, karena Anda tidak akan harus berurusan dengan itu di masa mendatang. Kepala sekolah yang berhasil memikirkan dua hingga tiga langkah ke depan. Mereka menangani gambar kecil dengan memperbaiki gambar besar. Mereka melihat melampaui keadaan khusus untuk sampai 
pada penyebab masalah. Mereka memahami bahwa menangani masalah inti dapat mencegah beberapa masalah kecil, yang berpotensi menghemat waktu dan uang (Meador, 2019).

\section{TEMPATKAN SISWA TERLEBIH DAHULU}

Komunikasi yang baik dengan masyarakat sekitar adalah kunci untuk dapat mengatasi masalah dan bisa bangkit dari keterpurukan manajemen pendidikan. Prinsip utama dan kepemimpinan wirausaha pendidikan adalah disiplin, kreatif, cerdas dan ulet (Qori' ah et al., 2017). Jangan biarkan media atau agenda politik menghalangi memutuskan apa yang terbaik untuk kebutuhan dan pembelajaran siswa Anda (Drewitt, 2017). 


\section{CARI BANTUAN LEBIH CEPAT DARIPADA}

\section{NANTI}

Pemimpin sekolah sebisanya tegas, toleran terhadap bawahannya dan mengayomi. Pendidikan adalah catatan masa lalu dan pengajaran masa kini untuk masa depan bangsa. Pendidikan adalah menyampaikan ilmu dan mentransformasi orang lain menjadi lebih baik (Fidiana et al., 2017). Menunggu untuk mengatasi masalah organisasi dapat berdampak buruk pada kesejahteraan sosial / emosional dan akademik siswa Anda. Cari tahu bagaimana sekolah siswa Anda dapat membantu. Beberapa sekolah memiliki pendukung sumber daya orang tua yang dapat mengarahkan Anda ke sumber daya di sekolah atau di masyarakat (Springer, 2019).

Demikian tulisan tentang wawasan untuk kepala sekolah yang sibuk. 


\section{REFERENCES}

Asitah, N., Usmawati, D. Z., Rosyidah, E., \& Purnomo, A. (2017). MI Hasyim Asyari Ilmu Harus Terus Mengarus. In Wirausaha Pendidikan Indonesia (Jilid 2). Sidoarjo: UNUSIDA Press.

Bauer, D. (2019). 200 Tips for Effective School Leaders. Retrieved June 16, 2019, from https://www.betterleadersbetterschools.com /200-tips-effective-school-leaders/

Covey, S. (1996). First things first. New York:

Simon and Schuster.

Drewitt, P. (2017). 25 tips for School Principals.

Retrieved June 13, 2019, from https://www.linkedin.com/pulse/25-tipsschool-principals-paul-drewitt Driscoll, M. (2018). 16 Success Tips for New 21st

Century Principals. Retrieved June 23, 2019, from

https://thinkstrategicforschools.com/16success-tips-new-21st-century-principals/ Edsys. (2016). 10 Awesome Tips to Manage School Discipline Issues. Retrieved June 29, 2019, from https://www.edsys.in/10awesome-tips-to-manage-school-disciplineissues/ 
Educational Leaders. (2019). Guides for managing your school. Retrieved June 22, 2019, from

http://www.educationalleaders.govt.nz/Man aging-your-school/Guides-for-managingyour-school

Fidiana, W., Istiana, Z., Rosyidah, E., \& Purnomo,

A. (2017). MINU Waru 2 Insan Berkilau Cahaya Manfaat. In Wirausaha Pendidikan Indonesia (Jilid 4). Sidoarjo: UNUSIDA Press. Irawan, D. E., Purnomo, A., Sutiksno, D. U., Abraham, J., Alamsyah, A., Saputra, D. H., .. Rosyidah, E. (2018). Kajian Pendidikan Tinggi IDRI untuk DPR RI dan Ristek Dikti 2018. Bandung: ITB Press.

Iskandar, A., Rizal, M., Kurniasih, N., Sutiksno, D. U., \& Purnomo, A. (2018). The Effects of Multimedia Learning on Students Achievement in Terms of Cognitive Test Results. Journal of Physics: Conference Series, 1114(1), 012019. https://doi.org/10.1088/17426596/1114/1/012019

Kane, A. (2018). 5 Essential Tips for Managing High School Students. Retrieved June 24, 2019, from https://theartofeducation.edu/2018/07/02/5 -essential-tips-for-managing-high-schoolstudents/ 
Maula, I., Asitah, N., Munjidah, A., Nahdiyah, K., Yuniarti, D., Sholichah, S. A., '. Qori' ah, S. (2018). Kontribusi Kreativitas Guru SD dalam Induksi Pembelajaran.

https://doi.org/http://doi.org/10.17605/OSF. IO/BS795

Maula, I., Mufidah, F. I., Rosyidah, E., \& Purnomo,

A. (2017). SD Antawirya Islamic Javanese School Mother is Culture. In Wirausaha Pendidikan Indonesia (Jilid 1). Sidoarjo: UNUSIDA Press.

Meador, D. (2019). 10 Things a Successful School Principal Does Differently. Retrieved June 27, 2019, from

https://www.thoughtco.com/things-asuccessful-school-principal-does-differently3194532

Munjidah, A., Zannah, I. P. N., Purnomo, A., \& Rosyidah, E. (2017). MI Thoriqussalam Berpegang Kepada Rosul. In Wirausaha Pendidikan Indonesia (Jilid 4). Sidoarjo: UNUSIDA Press.

Murray, J. (2018). Time Management Tips for School Leaders - Part I. Retrieved June 26, 2019, from

https://www.ccu.edu/blogs/cags/2018/01/ti me-management-tips-for-school-leaderspart-i/ 
Nahdiyah, K., Amrina, S., Purnomo, A., \&

Rosyidah, E. (2017). SD Taman Pendidikan Islam Porong Iman Kuat Bekal di Akhirat. In

Wirausaha Pendidikan Indonesia (Jilid 2).

Sidoarjo: UNUSIDA Press.

Purnomo, A. (2017). Pengertian Edupreneur.

https://doi.org/10.31227/osf.io/8fnu6

Qori' ah, S., Sholichah, S. A., Purnomo, A., \&

Rosyidah, E. (2017). Progresif Bumi Sholawat

dengan Kebenaran Semua Pasti Ada Jalan.

In Wirausaha Pendidikan Indonesia (Jilid 3).

Sidoarjo: UNUSIDA Press.

Sholichah, S. A., Istiqomah, A., Rosyidah, E., \&

Purnomo, A. (2017). MI Darun Najah Berfikir

Berkarya Berdzikir. In Wirausaha Pendidikan

Indonesia (Jilid 3). Sidoarjo: UNUSIDA Press.

Springer. (2019). Tips for Managing Organization.

Retrieved June 30, 2019, from

https://www.springer-ld.org/springer-

experience/center/parent-programs/tipsorganization 
Suci, S. H. A., Rosyidah, E., Asitah, N., Aini, N., Murni, A. W., Anam, F., ‥ Kuraesin, A. D. (2018). Learning from Picture and Picture Action Research : Enhancement of Counting Ability on Division of Numbers for Primary School Students. Journal of Physics:

Conference Series, 1114(1), 012044.

https://doi.org/10.1088/17426596/1114/1/012044

Watanabe-Crockett, L. (2018). The 10 School Leadership Best Practices That Make a Difference. Retrieved June 21, 2019, from https://www.wabisabilearning.com/blog/10school-leadership-best-practices

Yuniarti, D., Kautsari, M. F., Sholichah, F., Purnomo, A., \& Rosyidah, E. (2017). SMP SMA Al-Amin Ponpes Bahrul Hidayah Serahkan pada Allah Taala. In Wirausaha Pendidikan Indonesia (Jilid 1). Sidoarjo: UNUSIDA Press. 